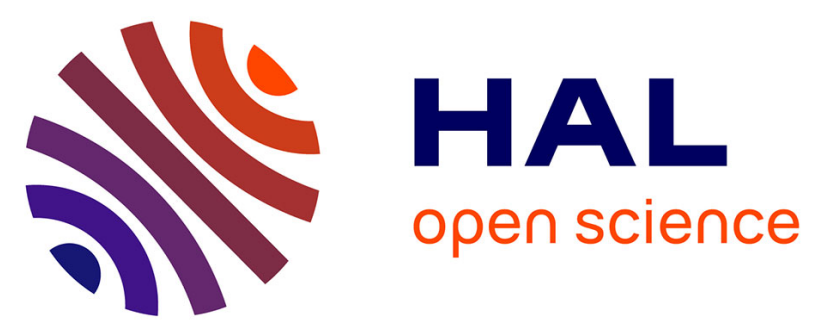

\title{
Laser Desorption Ionization Time-of-Flight Mass Spectrometry of Glasses and Amorphous Films from Ge-As-Se System
}

Katarina Sutorova, Lubomir Prokes, Virginie Nazabal, Emeline Baudet, Josef Havel, Petr Nemec

\section{To cite this version:}

Katarina Sutorova, Lubomir Prokes, Virginie Nazabal, Emeline Baudet, Josef Havel, et al.. Laser Desorption Ionization Time-of-Flight Mass Spectrometry of Glasses and Amorphous Films from Ge-As-Se System. Journal of the American Ceramic Society, 2016, 99 (11), pp.3594-3599. 10.1111/jace.14366 . hal-01414287

HAL Id: hal-01414287

https://hal-univ-rennes1.archives-ouvertes.fr/hal-01414287

Submitted on 18 Jul 2017

HAL is a multi-disciplinary open access archive for the deposit and dissemination of scientific research documents, whether they are published or not. The documents may come from teaching and research institutions in France or abroad, or from public or private research centers.
L'archive ouverte pluridisciplinaire HAL, est destinée au dépôt et à la diffusion de documents scientifiques de niveau recherche, publiés ou non, émanant des établissements d'enseignement et de recherche français ou étrangers, des laboratoires publics ou privés. 
Laser desorption ionisation time-of-flight mass spectrometry of glasses and amorphous films from Ge-As-Se system

Katarína Sútorová, ${ }^{\ddagger}$ Lubomír Prokeš, ${ }^{\ddagger},{ }^{\natural}$ Virginie Nazabal,,${ }^{\natural \dagger}$ Emeline Baudet, ${ }^{\natural}$ Josef Havel, ${ }^{\ddagger, \$}$, and Petr Němec ${ }^{l, *}$

${ }^{\ddagger}$ Department of Chemistry, Faculty of Science, Masaryk University, Kamenice 5/A14, 62500 Brno, Czech Republic

${ }^{\S}$ Department of Physical Electronics, Faculty of Science, Masaryk University, Kotlářská 2, 61137 Brno, Czech Republic

${ }^{\mathbb{}}$ CEPLANT, R\&D Centre for Low-Cost Plasma and Nanotechnology Surface Modifications, Masaryk University, Kotlářská 2, 61137 Brno, Czech Republic

॥ Department of Graphic Arts and Photophysics, Faculty of Chemical Technology, University of Pardubice, Studentská 573, 53210 Pardubice, Czech Republic

${ }^{\dagger}$ ISCR, Glasses and Ceramics team, UMR-CNRS 6226, University of Rennes 1, 35042 Rennes, France

\footnotetext{
*Author to whom correspondence should be addressed. Email: petr.nemec@ upce.cz
} 
Abstract

Laser Desorption Ionization Time-of-Flight Mass Spectrometry was exploited for the characterization of Ge-As-Se chalcogenide glasses and corresponding thin films fabricated using pulsed laser deposition. Main achievement of the paper is the determination of laser generated clusters' stoichiometry. The clusters observed were $\mathrm{As}_{b}{ }^{+}(b=1-3), \mathrm{Se}_{2}{ }^{-}$, binary $\mathrm{As}_{b} \mathrm{Se}^{+}(b=1-3), \mathrm{As}_{b} \mathrm{Se}_{c}^{-}(b=1-3, c=1-4), \mathrm{Ge}_{2} \mathrm{Se}_{c}^{-}(c=2-3), \mathrm{As}_{3} \mathrm{Se}_{2}^{+}, \mathrm{Ge}_{2} \mathrm{As}_{b}{ }^{-}(b=2-3)$, $\mathrm{Ge}_{3} \mathrm{As}_{b}^{-}(b=1-2), \mathrm{Ge}_{3} \mathrm{Se}_{4}^{-}, \mathrm{As}_{5} \mathrm{Se}_{c}^{-}(c=4-5), \mathrm{GeAsSe}_{4}^{-}, \mathrm{Ge}_{a} \mathrm{AsSe}_{5}^{-}(a=1-4), \mathrm{GeAs}_{2} \mathrm{Se}_{3}^{-}$, $\mathrm{GeAs}_{3} \mathrm{Se}_{2}{ }^{-}, \mathrm{Ge}_{2} \mathrm{As}_{2} \mathrm{Se}_{2}{ }^{-}, \mathrm{Ge}_{2} \mathrm{AsSe}_{c}{ }^{-}(c=6-7)$, and $\mathrm{GeAs}_{3} \mathrm{Se}_{c}^{-}(c=5-6)$ (in positive as well as in negative ion mode). The stoichiometries of identified species are compared with the structural units of the glasses/thin films revealed via Raman scattering spectra analysis. Some species are suggested to be fragments of bulk glass as well as thin films. Described method is useful also for the evaluation of the contamination of chalcogenide glasses or their thin films.

\section{Introduction}

Chalcogenide glasses and their thin films form an important class of amorphous materials with applications covering optical fibers, optical waveguides, sensors, phase-change memories, etc. Particularly interesting for optical applications is the good transparency of chalcogenide glasses in the mid-infrared spectral region combined with their high linear and nonlinear refractive indices. ${ }^{1-3}$

Various techniques are known and used to synthesize the amorphous chalcogenides in different forms like bulk glasses, optical fibers, and thin films. ${ }^{1,4}$ Among the chalcogenide glasses, the Ge-As-Se ternary system presents some attractive characteristics, such as one of the broadest glass-forming regions of any of the chalcogenides, relatively easy fabrication in 
bulk form, wide range of glass transition temperature $\left(\mathrm{T}_{\mathrm{g}}\right)$, and high nonlinear refractive index. ${ }^{5,}{ }^{6}$. Physical properties of bulk Ge-As-Se glasses were heavily reported: linear and nonlinear optical properties, ${ }^{7-11}$ structure, $,{ }^{8,9}, 12$ photoinduced processes,${ }^{13}$ etc. Fabrication and characterization of amorphous Ge-As-Se thin films was subject of deep research in last decade; pulsed laser deposition (PLD), ${ }^{14-18}$ thermal evaporation ${ }^{6,14,}$ 19-22 or radio-frequency magnetron sputtering ${ }^{23}$ were shown to be suitable deposition techniques; each of them possessing its own advantages and disadvantages. PLD technique seems to be promising according to its easy control of the deposition process, possibility to fabricate multilayered structures and often stoichiometric material transfer from the target to the films. ${ }^{24,25}$

An important role for the properties of amorphous chalcogenides is played by the presence of impurities. The measured optical losses in chalcogenide glasses are substantially higher than the intrinsic loses, mainly because of the presence of impurities in the glasses. There are three main sources of impurities in chalcogenide glasses: initial elements used for the synthesis, silica glass ampoule usually utilized for the synthesis of glass-forming melt, environment and the residual vacuum gases during the synthesis and treatment of glass/films. ${ }^{1}$ For illustration, laser ablation ionization of germanium which is typically used for the synthesis of Ge-based chalcogenide glasses, in spite of its high purity (99.9999\%), leads to the formation of large number of species; specifically, $\mathrm{Ge}_{m}$ clusters are accompanied by $\mathrm{Ge}_{m} \mathrm{H}_{n}$ ones, as observed by mass spectrometry (MS). ${ }^{26}$

It has been demonstrated that Laser Desorption Ionization Time-of-Flight Mass Spectrometry (LDI TOFMS) is a strong experimental method for the generation and identification of clusters of diverse solid state materials inclusive of amorphous chalcogenides as well as for the assessment of their contamination (oxygen, hydrogen and/or carbon impurities). ${ }^{27,28}$

In present work, Ge-As-Se glasses and PLD thin films were analysed through LDI 
TOFMS in order to acquire information regarding the structural fragments (and their contamination) present in the plasma emerging from the interaction of pulsed laser with solid state material. The obtained results would contribute to a deeper comprehension of the preparation and properties of amorphous chalcogenide thin films fabricated by pulsed laser deposition and generally via plasma deposition techniques.

\section{Experimental procedures}

Chalcogenide glasses from Ge-As-Se system (with $\mathrm{Ge}_{10} \mathrm{As}_{30} \mathrm{Se}_{60}, \mathrm{Ge}_{10} \mathrm{As}_{35} \mathrm{Se}_{55}, \mathrm{Ge}_{10} \mathrm{As}_{40} \mathrm{Se}_{50}$, $\mathrm{Ge}_{15} \mathrm{Ass}_{30} \mathrm{Se}_{55}$, and $\mathrm{Ge}_{20} \mathrm{As}_{20} \mathrm{Se}_{60}$ nominal compositions) were synthesized from high purity elements (Ge, As, and Se, 5-6 N) using the conventional melting and quenching technique. ${ }^{17}$

For the fabrication of thin films, UV PLD was employed using $25 \mathrm{~mm}$ targets made from above described bulk glasses, PLD setup consisting of a KrF excimer laser (248 nm, 300 \pm 3 $\mathrm{mJ}$ per pulse, $30 \mathrm{~ns}$ pulse duration, $20 \mathrm{~Hz}$ repetition rate), and a vacuum chamber (background pressure $<3 \times 10^{-4} \mathrm{~Pa}$ ). The substrates used for PLD (chemically cleaned microscope glass slides, $\mathrm{Si}$ wafers) were positioned parallel to the target surface at the target to substrate distance of $5 \mathrm{~cm}$. The energy fluence on the target was set at $\sim 2.6 \mathrm{~J} . \mathrm{cm}^{-2}$. Both the target and the substrates were rotated in off-axis geometry in order to avoid deep damage of the targets and to improve the thickness homogeneity of the films.

A diffractometer with Bragg-Brentano $\theta-\theta$ geometry (D8-Advance, Bruker AXS, Karlsruhe, Germany) was employed for the recording of X-ray diffraction (XRD) data. The diffraction angles were measured at room temperature from 5 to $65^{\circ}(2 \theta)$ in $0.02^{\circ}$ steps with a counting time of $5 \mathrm{~s}$ per step. To determine chemical composition of fabricated Ge-As-Se glasses/films, a scanning electron microscope equipped with an energy-dispersive X-ray analyzer (EDX, JSM 6400-OXFORD Link INCA, JEOL Ltd., Tokyo, Japan) was used. GeAs-Se materials were studied also using MIRA3 SEM (TESCAN, Brno, Czech Republic). 
The Raman scattering spectra of Ge-As-Se samples were measured at room temperature by LabRAM HR spectrometer (Horiba Jobin-Yvon, Villeneuve d'Ascq, France) with 785 nm laser as excitation source. The intensity of laser beam was kept at low level to avoid thermally induced structural transformations induced by absorption of high laser power densities. The frequency resolution of used configuration was $\sim 0.7 \mathrm{~cm}^{-1}$ per pixel.

Optical functions (refractive index and extinction coefficient spectral dependencies) of bulk glasses/thin Ge-As-Se films (and thicknesses in case of thin films) were obtained from the analysis of data measured using an ellipsometer with automatic rotating analyzer (VASE, J. A. Woollam Co., Inc., Lincoln, NE, USA). The measurement parameters were following: spectral region $300-2300 \mathrm{~nm}$ with wavelength steps of $10 \mathrm{~nm}(20 \mathrm{~nm}$ in case of target glasses), angles of incidence $50^{\circ}, 60^{\circ}$, and $70^{\circ}$. For the analysis of VASE data, Cody-Lorentz (CL) model was used. ${ }^{29}$

LDI TOFMS data were recorded within the powdered bulk glasses as well as corresponding thin films. The powders of Ge-As-Se glasses were prepared exploiting vibratory ball mill with agate mortar and grinding ball. For the mass spectrometry, $1 \mu \mathrm{L}$ of acetonitrile suspension of the powder $(1 \mathrm{mg} / \mathrm{mL})$ was deposited on the target plate and dried in a stream of air at room temperature. The target plate was always cleaned carefully with ethanol and double distilled water before the samples deposition. ${ }^{30}$

AXIMA Resonance mass spectrometer equipped with a quadrupole ion trap mass analyser (Kratos Analytical Ltd., Manchester, UK) employing a time-of-flight mass analyser was used for the measurement of LDI TOFMS data. Using AXIMA Resonance device, MS signal was recorded in $m / z$ ranges of 100-400, 250-1200, 800-3500, 1500-8000, and 3000-15000. The instrument used a delayed extraction. All the measurements were performed in both positive and negative reflectron ion modes. For necessary external mass calibration, a calibration standard (red phosphorus) was used in both ionisation modes. ${ }^{30}$ For LDI TOFMS, a UV 
source $\left(\mathrm{N}_{2}\right.$ laser operating at $337 \mathrm{~nm}$ ) with $3 \mathrm{~ns}$ pulse duration and repetition rate of $5 \mathrm{~Hz}$ was applied. The laser energy was scaled in arbitrary units (a.u.) from 0 to 180 ; this relative scale will be used hereinafter. Laser spot size on sample had circular shape with $\sim 150 \mu$ m diameter. Resulting laser energy fluence was $\sim 1 \mathrm{~J} . \mathrm{cm}^{-2}$. At least 1500 laser pulses were applied for the accumulation of each mass spectrum. Experimental isotopic patterns were compared with theoretical ones which were calculated through Launchpad software (Kompact version 2.9.3, 2011, Kratos Analytical Ltd., Manchester, UK).

\section{Results and discussion}

Fabricated glasses from Ge-As-Se system and corresponding thin films prepared by PLD were found to be amorphous and homogeneous; the films are without cracks/defects, according to optical/electron microscopy and XRD patterns. The morphology of the layers is of good quality as results from SEM micrographs. The chemical composition of Ge-As-Se glasses/thin films, as determined using EDX when averaging several measured points, is in good agreement with nominal one. In fact, all the measured compositions (for both bulks and films) are within $\sim 3$ at. \% variation of the nominal composition based on quantities of the elements used to prepare the glasses. Taking into account error limits of the EDX technique ( \pm 1 at. \%), one can conclude that the material transfer during PLD is close to target stoichiometry.

The thicknesses of all the films varied from $\sim 960$ to $\sim 1230 \mathrm{~nm}$, as determined by VASE data analysis. Obtained refractive indices spectral dependences for both, the bulk glasses and PLD thin films are illustrated in Fig. 1.; the data presented here show relatively good agreement between refractive indices of bulk glasses and thin films, especially in nearinfrared spectral region. The CL model reliability for the analysis of VASE data is confirmed by low values of mean square error of the fitting procedure $(<7.2)$. 
Mass spectra of Ge-As-Se samples were measured aiming at the stoichiometry determination of singly positively and negatively charged $\mathrm{Ge}_{a} \mathrm{As}_{b} \mathrm{Se}_{c}$ ions formed through LDI. Stoichiometry of species contained in the plasma was evaluated based on the comparison of experimental isotopic patterns with the theoretical ones. We note that the atomic weights of Ge, As, and Se are close to each other $\left(72.64,74.92\right.$, and 78.94 g.mol ${ }^{-1}$ for $\mathrm{Ge}, \mathrm{As}$, and $\mathrm{Se}$ ), therefore the isotopic envelopes are complex when number of $\mathrm{Ge}$, As or $\mathrm{Se}$ atoms are combined.

Firstly, we deal with the LDI TOFMS of bulk Ge-As-Se glasses. Here, we used similar methodology as the one we successfully applied earlier. ${ }^{30}$ The influence of laser energy on TOFMS spectra was studied in negative ion mode. We have found that the ionization started when the laser energy reached $\sim 80$ a.u. At higher laser energies, intensities of the LDI TOFMS signal gradually climbed. This observation is presented in Fig. 2. Sufficient mass resolution of the mass spectra and highest number of detected clusters in negative ion mode were identified at the laser energy $\sim 120-130$ a.u.

The MS spectrapeak with lowest mass was assigned to $\mathrm{Se}_{2}^{-}$ion. The further observed peaks were recognized as $\mathrm{AsSe}_{c}^{-}(c=2-3)$ and $\mathrm{As}_{3} \mathrm{Se}_{2}{ }^{-}$clusters. The $\mathrm{GeAsSe}_{4}^{-}$cluster was found to overlap with binary $\mathrm{As}_{3} \mathrm{Se}_{3}{ }^{-}$one (71 and $\left.29 \%\right)$. Percentage in brackets means the contribution of individual species to the overall peak intensity. Few oxidized clusters were also determined as $\mathrm{SeAsO}^{-}, \mathrm{SeAsO}_{2}^{-}, \mathrm{Se}_{2} \mathrm{AsO}^{-}, \mathrm{GeAsSeO}_{11}^{-}$, and $\mathrm{Ge}_{3} \mathrm{AsSeO}_{3}^{-}$. However, mentioned oxidized clusters were observed with low intensity and their content can be estimated below $<0.001 \%$ rel. Unfortunately, precise quantitative evaluation of oxygen containing species content is impossible as the exact correlation between the measured quantity (MS signal) and the number of generated ions is not known.

In addition to above mentioned clusters, also several lower intensity clusters were found. The overlap of binary $\mathrm{Ge}_{2} \mathrm{As}_{2}{ }^{-}$and $\mathrm{Ge}_{3} \mathrm{As}^{-}$clusters (83 and $17 \%$ ) was observed. In higher 
mass range (above $300 \mathrm{~m} / \mathrm{z}$ ), other entities take place. These were established as overlap of $\mathrm{Ge}_{2} \mathrm{As}_{3}{ }^{-}$and $\mathrm{Ge}_{3} \mathrm{As}_{2}{ }^{-}$species (46 and $\left.57 \%\right)$. In addition, ternary $\mathrm{Ge}_{a} \mathrm{AsSe}_{5}{ }^{-}(a=1-2)$ clusters were identified. The heaviest clusters were found as overlap of ternary clusters with binary one for $m / z$ values $\sim 690$ and $\sim 772 ; \mathrm{Ge}_{2} \mathrm{AsSe}_{6}{ }^{-}$one with $\mathrm{GeAs}_{3} \mathrm{Se}_{5}{ }^{-}$and $\mathrm{As}_{5} \mathrm{Se}_{4}{ }^{-}$clusters $(43,22$ and $35 \%), \mathrm{Ge}_{2} \mathrm{AsSe}_{7}{ }^{-}$one with $\mathrm{GeAs}_{3} \mathrm{Se}_{6}{ }^{-}$and $\mathrm{As}_{5} \mathrm{Se}_{5}^{-}$clusters (45, 18 and $37 \%$ ). Finally, $\mathrm{Ge}_{3} \mathrm{AsSe}_{5}{ }^{-}$and $\mathrm{Ge}_{4} \mathrm{AsSe}_{5}{ }^{-}$species were detected. No more clusters were identified at $\mathrm{m} / \mathrm{z}$ values over 800 . Fig. 3 presents a comparison between experimental and model mass spectra in $m / z$ range 150-320; we note a perfect agreement.

The influence of laser energy on TOFMS spectra was studied also in positive ion mode; the ionization started when the laser energy reached $\sim 80-90$ a.u. At higher laser energies, intensities of the observed clusters decreased with rising the energy of the laser. At the laser energy 120 a.u., mass spectra have satisfactory mass resolution, intensity of signal, and highest number of clusters in positive ion mode. The peaks detected were identified as signal coming from $\mathrm{As}_{b} \mathrm{Se}^{+}(b=1-3)$ clusters and $\mathrm{As}_{3} \mathrm{Se}_{2}{ }^{+}$one.

We turn to the analysis of Ge-As-Se thin films. In case of LDI TOFMS analysis of Ge-AsSe PLD thin films performed in negative ion mode, the ionization began when the energy of the laser reached $\sim 100$ a.u. Also here, at higher laser energies, intensities of the observed clusters gradually increased. At the same laser energy as for bulk glasses ( 120 a.u), mass spectra containing highest number of ionized species in negative ion mode were recorded.

The lowest mass peak was identified as $\mathrm{Se}_{2}^{-}$ion. The further observed peaks were recognized as $\mathrm{AsSe}_{c}^{-}(c=2-3)$ and $\mathrm{As}_{3} \mathrm{Se}_{2}^{-}$clusters. The $\mathrm{GeAsSe}_{4}^{-}$cluster was found to overlap with binary $\mathrm{As}_{3} \mathrm{Se}_{3}^{-}$one (71 and $29 \%$ ). In addition to above mentioned clusters several low intensity clusters were detected. The overlap of $\mathrm{Ge}_{2} \mathrm{Se}_{2}{ }^{-}$with $\mathrm{As}_{2} \mathrm{Se}_{2}{ }^{-}$cluster was found (52 and $48 \%$ ). The other observed peaks were identified as overlaps of binary $\mathrm{Ge}_{3} \mathrm{As}_{2}{ }^{-}$ one with $\mathrm{As}_{2} \mathrm{Se}_{3}^{-}$and $\mathrm{Ge}_{2} \mathrm{Se}_{3}^{-}$clusters (6, 63 and $31 \%$ ); ternary $\mathrm{Ge}_{2} \mathrm{As}_{2} \mathrm{Se}_{2}^{-}$one with 
$\mathrm{GeAs}_{2} \mathrm{Se}_{3}{ }^{-}$and $\mathrm{GeAs}_{3} \mathrm{Se}_{2}{ }^{-}$clusters $\left(9,27\right.$ and $64 \%$ ), and binary $\mathrm{Ge}_{3} \mathrm{Se}_{4}{ }^{-}$cluster with $\mathrm{As}_{3} \mathrm{Se}_{4}{ }^{-}$ one (33 and $77 \%$ ). No more clusters were found for $\mathrm{m} / \mathrm{z}$ values over 600 . It is worth noting that in contrast with the MS analysis of bulk glasses, no clusters containing oxygen were detected in Ge-As-Se thin films. This difference could be explained by the procedure of MS samples preparation. The films were processed by PLD under vacuum. In case of bulk samples, the powders were made using vibratory ball mill without protecting inert atmosphere, which may lead to the slight surface oxidation. As we expect that oxidation proceeds in very top layer of the chalcogenide powder particles only, the presence of oxidized species should be marginal. This is confirmed by MS spectra; estimated content of oxidized clusters is below $<0.001 \%$ rel. as mentioned above.

When analyzing Ge-As-Se thin films in positive ion mode, impact of varying laser energy was also investigated. Similarly to negative ion mode, the ionization started at the laser energy 100 a.u.. At higher laser energies, intensities of the observed clusters gradually increased (Fig. 4). Mass spectra in positive ion mode present adequate resolution, signal intensity, and highest number of detected species after reaching 120-130 a.u. laser energy. The MS spectra peaks were identified as $\mathrm{As}_{b} \mathrm{Se}^{+}(b=1-3)$ clusters and $\mathrm{As}_{3} \mathrm{Se}_{2}{ }^{+}$one as for the analysis of bulk Ge-As-Se glasses. Also, arsenic clusters $\mathrm{As}_{b}{ }^{+}(b=1-3)$ were identified.

For reader's convenience, a summary of species identified in mass spectra of plasma generated from all Ge-As-Se samples is given in Table I. It is worthy to point out that some species summarized in Table I. are common for both types of samples (bulk glasses and thin films); these are $\mathrm{As}_{b} \mathrm{Se}^{+}(b=1-3), \mathrm{As}_{3} \mathrm{Se}_{2}{ }^{+/-}, \mathrm{Se}_{2}^{-}, \mathrm{AsSe}_{c}{ }^{-}(c=2-3), \mathrm{GeAsSe}_{4}^{-}$, and $\mathrm{As}_{3} \mathrm{Se}_{3}{ }^{-}$.

On the basis of Raman scattering spectra (Fig. 5), the structure of Ge-As-Se bulk glasses can be determined. The local structure is formed by different structural motifs as described below. First, the presence of $\mathrm{GeSe}_{4}$ corner-sharing tetrahedra is documented through Raman bands peaking at $\sim 193-198$ and $\sim 300 \mathrm{~cm}^{-1}$ originating from $\mathrm{A}_{1}\left(v_{1}\right)$ symmetric stretching and 
$\mathrm{F}_{2}$ asymmetric vibration mode of $\mathrm{GeSe}_{4}$ corner-sharing tetrahedral, respectively. Second, Raman band peaking at $\sim 215 \mathrm{~cm}^{-1}$ is attributed to the "companion" mode due to the vibrations of $\mathrm{GeSe}_{4}$ tetrahedra sharing their edges. Homopolar Ge-Ge bonds can also be presented ${ }^{17}$ in Ge-Ge $\mathrm{GSe}_{4-\mathrm{m}}, \mathrm{m}=1,2,3,4$ structural units with wide Raman band centered at $\sim 270 \mathrm{~cm}^{-1}$ and a shoulder at $\sim 170 \mathrm{~cm}^{-1}$. Arsenic based structural motifs are represented by $\mathrm{AsSe}_{3}$ pyramids identified via stretching vibration modes at $\sim 224-229 \mathrm{~cm}^{-1}$. The presence of cage-like $\mathrm{As}_{4} \mathrm{Se}_{3(4)}$ molecules containing homopolar As-As bonds can be connected with the Raman features at $\sim 238,196,256,248$, and $190 \mathrm{~cm}^{-1} .^{17,31}$

The Raman spectra of as-deposited Ge-As-Se layers show similar features as the bulk glasses do (Fig. 5). The widths of individual bands are generally larger for the thin films when compared with bulk glasses, which is an indication of a larger degree of disorder in the films. The local structure of Ge-As-Se films is, in accordance with parent bulk glasses, formed by $\mathrm{GeSe}_{4}$ corner- and edge-sharing tetrahedral and arsenic-based structural units as discussed below.

The differences between Raman spectra of bulk Ge-As-Se glasses and corresponding thin films concern mainly $\sim 210-260 \mathrm{~cm}^{-1}$ region for glasses/films containing lower amount of selenium $\left(\mathrm{Ge}_{10} \mathrm{As}_{35} \mathrm{Se}_{55}, \mathrm{Ge}_{10} \mathrm{As}_{40} \mathrm{Se}_{50}, \mathrm{Ge}_{15} \mathrm{As}_{30} \mathrm{Se}_{55}\right)$. Specifically, in case of Ge-As-Se films with lower selenium content, the Raman bands in $\sim 210-260 \mathrm{~cm}^{-1}$ region are almost featureless. This behaviour was already reported for As-Se PLD films, where for selenium under-stoichiometric compositions ( $\mathrm{As}_{50} \mathrm{Se}_{50}, \mathrm{As}_{57} \mathrm{Se}_{43}, \mathrm{As}_{60} \mathrm{Se}_{40}$ ), amorphous layers present featureless character of Raman response in discussed spectral range while for bulk glasses several bands can be distinguished. ${ }^{32}$ Further, for $\mathrm{As}_{40} \mathrm{Se}_{60}$ stoichiometric composition, Raman spectra of the bulk glass and as-deposited PLD films are almost identical, again featureless. ${ }^{33}$ Moreover, the shape of Raman spectra of as-deposited PLD As-rich As-Se layers is similar to stoichiometric $\mathrm{As}_{40} \mathrm{Se}_{60}$ glasses/PLD films. Observed Raman spectra of As-rich As-Se bulk 
glasses/PLD films are interpreted in terms of local structure differences between the glasses and films. The structure of As-rich As-Se bulk glasses is formed by $\mathrm{AsSe}_{3}$ pyramids, cagelike molecular units $\left(\mathrm{As}_{4} \mathrm{Se}_{3(4)}\right)$, and arsenic clusters. In contrast, the structure of corresponding as-prepared PLD thin films is probably formed mainly by As-based pyramids $\left(\mathrm{AsSe}_{3}, \mathrm{As}_{2} \mathrm{Se}_{2}, \mathrm{As}_{3} \mathrm{Se}\right.$, and eventually $\left.\mathrm{As}_{4}\right)$ with vibrational frequencies near the frequencies of $\mathrm{AsSe}_{3}$ pyramids. ${ }^{32}$ Nevertheless, presence of some $\mathrm{As}_{4} \mathrm{Se}_{3(4)}$ cage-like molecules in the structure of Ge-As-Se PLD films is also probable. We believe that analogous interpretation is valid also for studied Ge-As-Se glasses/PLD films with lower selenium content.

To conclude, glassy network of Ge-As-Se glasses and amorphous layers is mainly formed by $\mathrm{GeSe}_{4}$ tetrahedra and different arsenic-based structural units. In accordance with the chemical composition of the samples, homopolar Ge-Ge and As-As bonds are also expected. The results of LDI TOFMS analysis may bring proof for some of above mentioned structural units. For instance, $\mathrm{AsSe}_{3}{ }^{-}$entities obviously validate the presence of $\mathrm{AsSe}_{3}$ pyramidal units in the structure of Ge-As-Se glasses and/or thin films. Evidence of $\mathrm{As}_{b} \mathrm{Se}^{+}(b=1-3)$ and $\mathrm{As}_{2} \mathrm{Se}_{2}{ }^{-}$ species is coherent with the presence of arsenic-based pyramids ( $\mathrm{AsSe}_{3}, \mathrm{As}_{2} \mathrm{Se}_{2}, \mathrm{As}_{3} \mathrm{Se}$ ). $\mathrm{As}_{3} \mathrm{Se}_{2}{ }^{+-}, \mathrm{As}_{3} \mathrm{Se}_{3}{ }^{-}$, and $\mathrm{As}_{2} \mathrm{Se}_{3}{ }^{-}$clusters are probably connected with the fragmentation of $\mathrm{As}_{4} \mathrm{Se}_{3(4)}$ cage-like molecules. The fragmentation of $\mathrm{As}_{4} \mathrm{Se}_{3(4)}$ cage-like molecules and/or arsenic-based pyramids can also lead to the presence of $\mathrm{Se}_{2}{ }^{-}$and $\mathrm{AsSe}_{2}{ }^{-}$species in the plasma. Identification of $\mathrm{As}_{b}{ }^{+}(b=1-3)$ species can be attributed to the fragmentation of arsenic-rich As-Se pyramids, whose presence is expected in the structure of Ge-As-Se films.

Contrary, in case of $\mathrm{GeSe}_{4}$ tetrahedra, which constitute one of the most significant structural entities of Ge-As-Se glasses/films as proved by Raman data, LDI TOFMS did not detect clear evidence of such structural units. The LDI TOFMS data recorded in this work show much lower number of germanium containing species than would be anticipated taking into account the stoichiometry of materials under study. This observation might be connected 
with difficult ionization of Ge-based species. ${ }^{28}$

Some binary (such as $\mathrm{Ge}_{2} \mathrm{As}_{2}^{-}, \mathrm{Ge}_{3} \mathrm{As}^{-}, \mathrm{Ge}_{2} \mathrm{As}_{3}{ }^{-}, \mathrm{Ge}_{3} \mathrm{As}_{2}^{-}, \mathrm{As}_{5} \mathrm{Se}_{4}^{-}, \mathrm{As}_{5} \mathrm{Se}_{5}^{-}, \mathrm{Ge}_{2} \mathrm{Se}_{2}^{-}$, $\mathrm{Ge}_{2} \mathrm{Se}_{3}{ }^{-}, \mathrm{Ge}_{3} \mathrm{Se}_{4}{ }^{-}$or $\mathrm{As}_{3} \mathrm{Se}_{4}{ }^{-}$one) and ternary species identified in mass spectra of Ge-As-Se glasses and thin films (Table I.) do not agree with structural motifs found by the analysis of Raman spectra of Ge-As-Se glasses/thin films. The presence of unexpected species identified by LDI TOFMS likely originates from deeper fragmentation of basic structural units. Due to very high energy of species forming plasma plume, one should take into account also reactions ongoing in plasma state.

Unfortunately, quantitative correlation between Raman data and LDI TOFMS results is difficult to obtain. This is mainly due to the fact that precise correlation between measured mass spectrometry signal and the number of generated ion species is not known. Further problem is the fragmentation of the glass structure which is probably complex process and the same fragments can be formed from different glass structural units or different fragments can be formed from the same structural unit. The fragmentation can also be different for varying glass composition.

To conclude, the species which originate from the interaction of Ge-As-Se glasses with high energy laser pulses partially correspond with the structural units observed in original material. This conclusion can be supported by the fact that the stoichiometry of the species identified through LDI TOFMS does not vary dramatically with increasing laser energy.

\section{Conclusions}

In this paper, refractive index (through spectroscopic ellipsometry) and structure (via Raman scattering spectroscopy) of Ge-As-Se bulk glasses and pulsed laser deposited thin films were studied. Refractive indices of bulk glasses and thin films are in satisfactory agreement in nearinfrared spectral region. In case of low Se content, the structure of the glasses is partly 
different from PLD films. Apart from $\mathrm{GeSe}_{4}$ tetrahedra, bulk glasses contain $\mathrm{AsSe}_{3}$ pyramids, cage-like molecular units $\left(\mathrm{As}_{4} \mathrm{Se}_{3(4)}\right)$, and arsenic clusters. In contrast, the structure of asprepared PLD thin films is probably formed by As-based pyramids ( $\mathrm{AsSe}_{3}, \mathrm{As}_{2} \mathrm{Se}_{2}, \mathrm{As}_{3} \mathrm{Se}$, and eventually $\mathrm{As}_{4}$ ). Laser desorption ionization time-of-flight mass spectrometry was used for the analysis of plasma formed from Ge-As-Se chalcogenide materials. In positive ion mode, $\mathrm{As}_{b}{ }^{+}(b=1-3), \mathrm{As}_{b} \mathrm{Se}^{+}(b=1-3)$, and $\mathrm{As}_{3} \mathrm{Se}_{2}{ }^{+}$species were found. In negative ion mode, $\mathrm{Se}_{2}{ }^{-}, \mathrm{As}_{b} \mathrm{Se}_{c}^{-}(b=1-3, c=1-4), \mathrm{Ge}_{2} \mathrm{Se}_{c}^{-}(c=2-3), \mathrm{Ge}_{2} \mathrm{As}_{b}^{-}(b=2-3), \mathrm{Ge}_{3} \mathrm{As}_{b}^{-}(b=1-2)$, $\mathrm{Ge}_{3} \mathrm{Se}_{4}^{-}, \mathrm{As}_{5} \mathrm{Se}_{c}^{-}(c=4-5), \mathrm{GeAsSe}_{4}^{-}, \mathrm{Ge}_{a} \mathrm{AsSe}_{5}^{-}(a=1-4), \mathrm{GeAs}_{2} \mathrm{Se}_{3}^{-}, \mathrm{GeAs}_{3} \mathrm{Se}_{2}{ }^{-}, \mathrm{Ge}_{2} \mathrm{As}_{2} \mathrm{Se}_{2}^{-}$, $\mathrm{Ge}_{2} \mathrm{AsSe}_{c}{ }^{-}(c=6-7)$, and $\mathrm{GeAs}_{3} \mathrm{Se}_{c}^{-}(c=5-6)$ entities were identified. Some identified species were observed for both, bulk glasses and thin films. LDI TOF MS showed also the presence of some oxygen-containing impurities in the studied bulk materials. Some of clusters such as $\mathrm{AsSe}_{3}{ }^{-}, \mathrm{As}_{b} \mathrm{Se}^{+}(b=1-3)$, and $\mathrm{As}_{2} \mathrm{Se}_{2}{ }^{-}$detected in mass spectra suggest to be species present in the structure of original glasses as well as thin films fabricated by pulsed laser deposition. Other charged clusters detected in the plasma plume do not seem to be involved in the structure of Ge-As-Se glasses/films; such species are probably created through the reactions of highly energetic species in the plasma plume or due to deeper fragmentation of basic structural units. Laser desorption ionization time-of-flight mass spectrometry technique confirmed high purity of synthesized Ge-As-Se glasses and thin films as only few species containing oxygen were identified.

\section{Acknowledgements}

Support from the Czech Science Foundation (Project No. 13-05082S) is greatly acknowledged. SIR-platform of ScanMAT is acknowledged by V. N. This research has been also supported by CEPLANT, the project R\&D center for low-cost plasma and nanotechnology surface modifications CZ.1.05/2.1.00/03.0086 funded by European 
Regional Development Fund. Authors are grateful to Dr. J. Jurmanová for SEM measurements. 


\section{References}

1. J. L. Adam and X. Zhang, "Chalcogenide Glasses: Preparation, Properties and Applications," pp. 1-682. Woodhead Publishing, (2013).

2. B. J. Eggleton, B. Luther-Davies, and K. Richardson, "Chalcogenide photonics," Nature Photonics, 5 [3] 141-148 (2011).

3. P. Lucas, Z. Y. Yang, M. K. Fah, T. Luo, S. B. Jiang, C. Boussard-Pledel, M. L. Anne, and B. Bureau, "Telluride glasses for far infrared photonic applications," Optical Materials Express, 3 [8] 1049-1058 (2013).

4. J. L. Adam, L. Calvez, J. Troles, and V. Nazabal, "Chalcogenide Glasses for Infrared Photonics," International Journal of Applied Glass Science, 6 [3] 287-294 (2015).

5. Z. U. Borisova, "Glassy Semiconductors," pp. 505. Plenum: New York, (1981).

6. D. A. P. Bulla, R. P. Wang, A. Prasad, A. V. Rode, S. J. Madden, and B. LutherDavies, "On the properties and stability of thermally evaporated Ge-As-Se thin films," Appl. Phys. A-Mater. Sci. Process., 96 [3] 615-625 (2009).

7. T. Wang, X. Gai, W. H. Wei, R. P. Wang, Z. Y. Yang, X. Shen, S. Madden, and B. Luther-Davies, "Systematic z-scan measurements of the third order nonlinearity of chalcogenide glasses," Optical Materials Express, 4 [5] 1011-1022 (2014).

8. C. J. Zha, R. P. Wang, A. Smith, A. Prasad, R. A. Jarvis, and B. Luther-Davies, "Optical properties and structural correlations of GeAsSe chalcogenide glasses," J. Mater. Sci.-Mater. Electron., 18 S389-S392 (2007).

9. A. Prasad, C. J. Zha, R. P. Wang, A. Smith, S. Madden, and B. Luther-Davies, "Properties of $\mathrm{Ge}_{\mathrm{x}} \mathrm{As}_{\mathrm{y}} \mathrm{Se}_{1-\mathrm{x}-\mathrm{y}}$ glasses for all-optical signal processing," Opt. Express, 16 [4] 2804-2815 (2008).

10. J. T. Gopinath, M. Soljacic, E. P. Ippen, V. N. Fuflyigin, W. A. King, and M. Shurgalin, "Third order nonlinearities in Ge-As-Se-based glasses for telecommunications applications," J. Appl. Phys., 96 [11] 6931-6933 (2004).

11. C. Quemard, F. Smektala, V. Couderc, A. Barthelemy, and J. Lucas, "Chalcogenide glasses with high non linear optical properties for telecommunications," J. Phys. Chem. Solids, 62 [8] 1435-1440 (2001).

12. R. P. Wang, A. V. Rode, D. Y. Choi, and B. Luther-Davies, "Investigation of the structure of $\mathrm{Ge}_{\mathrm{x}} \mathrm{As}_{\mathrm{y}} \mathrm{Se}_{1-\mathrm{x}-\mathrm{y}}$ glasses by x-ray photoelectron spectroscopy," J. Appl. Phys., 103 [8] 083537 (2008).

13. L. Calvez, Z. Y. Yang, and P. Lucas, "Light-induced matrix softening of Ge-As-Se network glasses," Phys. Rev. Lett., 101 [17] 177402 (2008).

14. R. A. Jarvis, R. P. Wang, A. V. Rode, C. Zha, and B. Luther-Davies, "Thin film deposition of $\mathrm{Ge}_{33} \mathrm{As}_{12} \mathrm{Se}_{55}$ by pulsed laser deposition and thermal evaporation: Comparison of properties," J. Non-Cryst. Solids, 353 [8-10] 947-949 (2007).

15. A. Zakery and M. Hatami, "Nonlinear optical properties of pulsed-laserdeposited GeAsSe films and simulation of a nonlinear directional coupler switch," J. Opt. Soc. Am. B-Opt. Phys., 22 [3] 591-597 (2005).

16. D. Y. Choi, S. Madden, A. Rode, R. Wang, and B. Luther-Davies, "Fabrication of low loss $\mathrm{Ge}_{33} \mathrm{As}_{12} \mathrm{Se}_{55}$ (AMTIR-1) planar waveguides," Appl. Phys. Lett., 91 [1] 
011115 (2007).

17. P. Nemec, S. Zhang, V. Nazabal, K. Fedus, G. Boudebs, A. Moreac, M. Cathelinaud, and X.-H. Zhang, "Photo-stability of pulsed laser deposited $\mathrm{Ge}_{\mathrm{x}} \mathrm{As}_{\mathrm{y}} \mathrm{Se}_{100-\mathrm{x}-\mathrm{y}}$ amorphous thin films," Opt. Express, 18 [22] 22944-22957 (2010).

18. P. Hawlova, M. Olivier, F. Verger, V. Nazabal, and P. Nemec, "Photosensitivity of pulsed laser deposited $\mathrm{Ge}_{20} \mathrm{As}_{20} \mathrm{Se}_{60}$ and $\mathrm{Ge}_{10} \mathrm{As}_{30} \mathrm{Se}_{60}$ amorphous thin films," Mater. Res. Bull., 48 [10] 3860-3864 (2013).

19. X. Su, R. Wang, B. Luther-Davies, and L. Wang, "The dependence of photosensitivity on composition for thin films of $\mathrm{Ge}_{\mathrm{x}} \mathrm{As}_{\mathrm{y}} \mathrm{Se}_{1-\mathrm{x}-\mathrm{y}}$ chalcogenide glasses," Appl. Phys. A-Mater. Sci. Process., 113 [3] 575-581 (2013).

20. K. L. Yan, R. Wang, K. Vu, S. Madden, K. Belay, R. Elliman, and B. Luther-Davies, "Photoluminescence in Er-doped Ge-As-Se chalcogenide thin films," Optical Materials Express, 2 [9] 1270-1277 (2012).

21. P. Khan, H. Jain, and K. V. Adarsh, "Role of Ge : As ratio in controlling the lightinduced response of a-GexAs35-xSe65 thin films," Scientific Reports, 44029 (2014).

22. G. Yang, H. S. Jain, A. T. Ganjoo, D. H. Zhao, Y. S. Xu, H. D. Zeng, and G. R. Chen, "A photo-stable chalcogenide glass," Opt. Express, 16 [14] 10565-10571 (2008).

23. D. A. Turnbull, J. S. Sanghera, V. Nguyen, and I. D. Aggarwal, "Fabrication of waveguides in sputtered films of GeAsSe glass via photodarkening with above bandgap light," Mater. Lett., 58 [1-2] 51-54 (2004).

24. P. Nemec, J. Charrier, M. Cathelinaud, M. Allix, J. L. Adam, S. Zhang, and V. Nazabal, "Pulsed laser deposited amorphous chalcogenide and aluminosilicate thin films and their multilayered structures for photonic applications," Thin Solid Films, 539 226-232 (2013).

25. V. Nazabal, F. Charpentier, J.-L. Adam, P. Nemec, H. Lhermite, M.-L. BrandilyAnne, J. Charrier, J.-P. Guin, and A. Moreac, "Sputtering and Pulsed Laser Deposition for Near- and Mid-Infrared Applications: A Comparative Study of $\mathrm{Ge}_{25} \mathrm{Sb}_{10} \mathrm{~S}_{65}$ and $\mathrm{Ge}_{25} \mathrm{Sb}_{10} \mathrm{Se}_{65}$ Amorphous Thin Films," International Journal of Applied Ceramic Technology, 8 [5] 990-1000 (2011).

26. J. Houska, E. M. Pena-Mendez, J. Kolar, J. Prikryl, M. Pavlista, M. Frumar, T. Wagner, and J. Havel, "Laser desorption time-of-flight mass spectrometry of atomic switch memory Ge2Sb2Te5 bulk materials and its thin films," Rapid Communications in Mass Spectrometry, 28 [7] 699-704 (2014).

27. S. D. Pangavhane, P. Nemec, T. Wagner, J. Janca, and J. Havel, "Laser desorption ionization time-of-flight mass spectrometric study of binary As-Se glasses," Rapid Communications in Mass Spectrometry, 24 [14] 2000-2008 (2010).

28. S. D. Pangavhane, P. Nemec, V. Nazabal, A. Moreac, P. Jovari, and J. Havel, "Laser desorption ionization time-of-flight mass spectrometry of erbiumdoped Ga-Ge-Sb-S glasses," Rapid Communications in Mass Spectrometry, 28 [11] 1221-1232 (2014).

29. G. D. Cody, pp. 11. in Semiconductors and semimetals, Vol. 21B. Edited by J. I. Pankove. Academic, Orlando, FL, 1984.

30. K. Sutorova, L. Prokes, V. Nazabal, M. Bouska, J. Havel, and P. Nemec, "Laser Desorption Ionisation Time-of-Flight Mass Spectrometry of Chalcogenide 
Glasses from $\left(\mathrm{GeSe}_{2}\right)_{100-x}\left(\mathrm{Sb}_{2} \mathrm{Se}_{3}\right)_{x}$ System," J. Am. Ceram. Soc., 98 [12] 4107-4110 (2015).

31. G. Yang, B. Bureau, T. Rouxel, Y. Gueguen, O. Gulbiten, C. Roiland, E. Soignard, J. L. Yarger, J. Troles, J.-C. Sangleboeuf, and P. Lucas, "Correlation between structure and physical properties of chalcogenide glasses in the $\mathrm{As}_{\mathrm{x}} \mathrm{Se}_{1-\mathrm{x}}$ system," Phys. Rev. B, 82 [19] (2010).

32. P. Nemec, J. Jedelsky, M. Frumar, M. Stabl, and Z. Cernosek, "Structure, optical properties and their photo-induced changes in $\mathrm{As}_{\mathrm{x}} \mathrm{Se}_{100-\mathrm{x}}(\mathrm{x}=50,57.1,60)$ amorphous thin films prepared by pulsed laser deposition," Thin Solid Films, 484 140-145 (2005).

33. P. Nemec, J. Jedelsky, M. Frumar, M. Stabl, and M. Vlcek, "Structure, Thermally and Optically Induced Effects in Amorphous $\mathrm{As}_{2} \mathrm{Se}_{3}$ Films Prepared by Pulsed Laser Deposition," J. Phys. Chem. Solids, 65 [7] 1253-1258 (2004). 
Figure captions

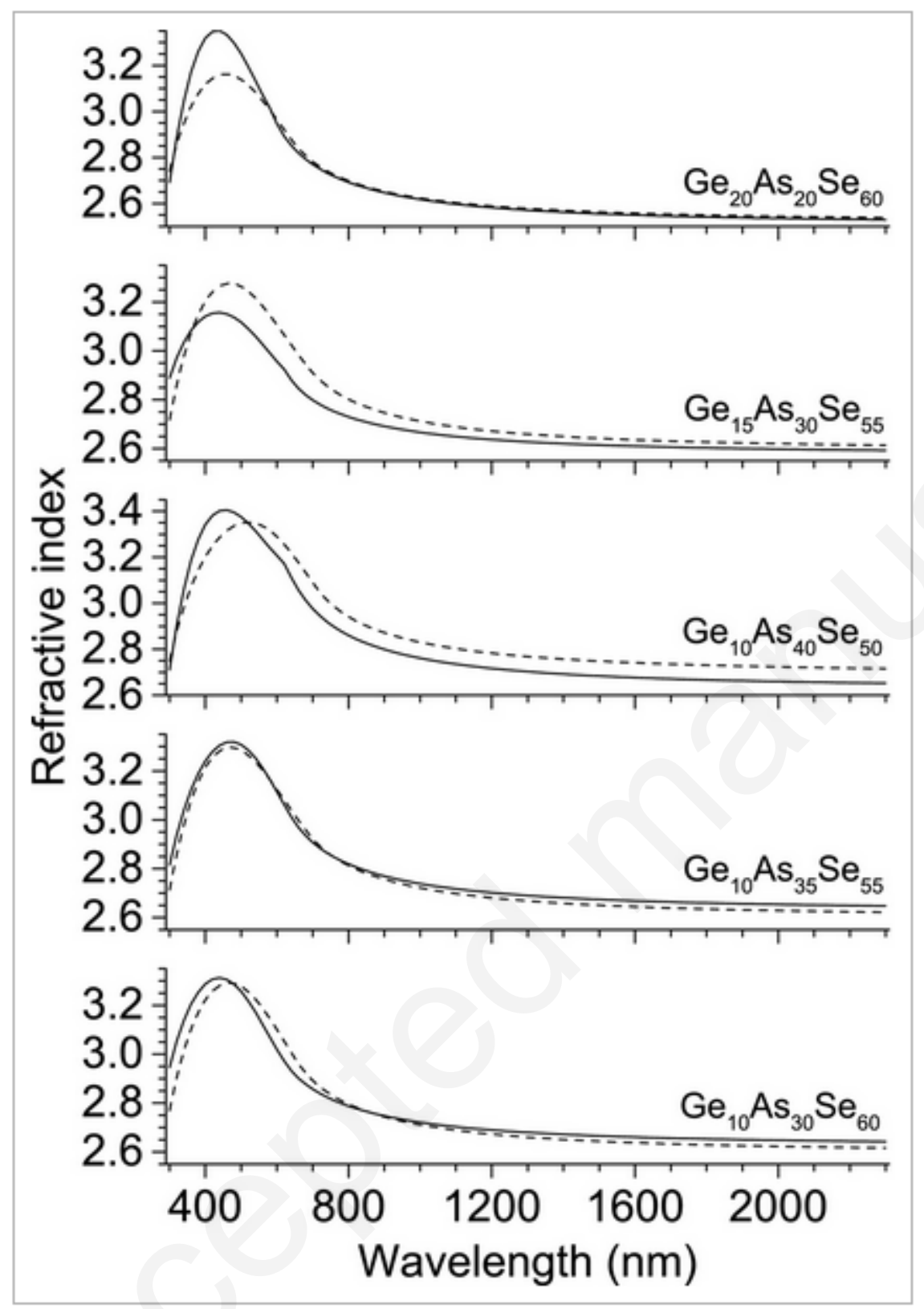

Fig. 1. Refractive indices spectral dependencies of bulk Ge-As-Se glasses and corresponding PLD thin films obtained from the analysis of VASE data using CL model. Full and dashed curves stand for bulk glasses and PLD layers, respectively. 


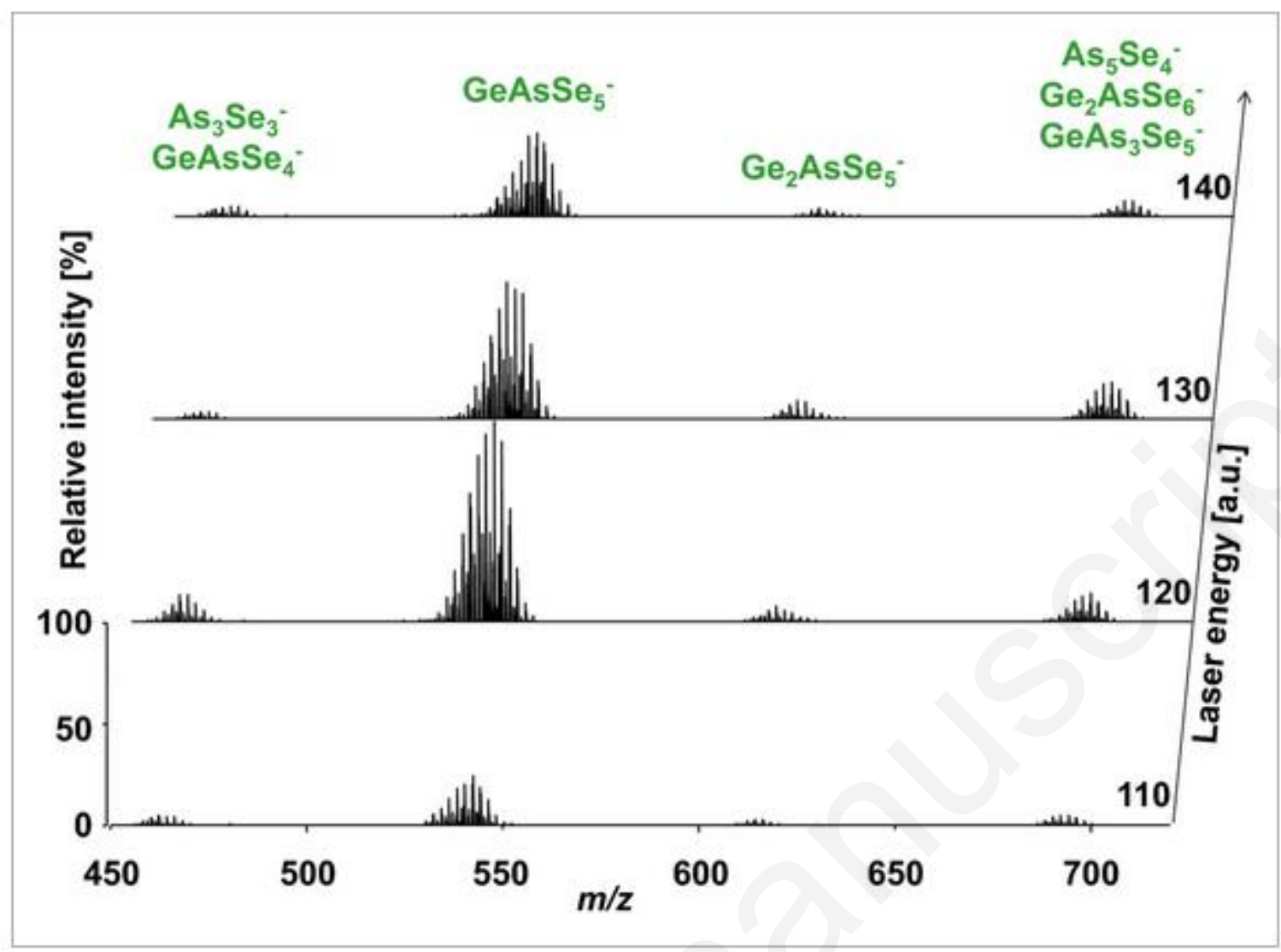

Fig. 2. The effect of laser energy on the LDI TOF mass spectra of the bulk $\mathrm{Ge}_{10} \mathrm{As}_{40} \mathrm{Se}_{50}$ sample showing the formation of $\mathrm{As}_{3} \mathrm{Se}_{3}{ }^{-}$cluster overlapped with $\mathrm{GeAsSe}_{4}{ }^{-}$one, $\mathrm{Ge}_{a} \mathrm{AsSe}_{5}{ }^{-}$( $a$ $=$ 1-2) clusters, and overlap of $\mathrm{As}_{5} \mathrm{Se}_{4}^{-}$one with $\mathrm{Ge}_{2} \mathrm{AsSe}_{6}{ }^{-}$and $\mathrm{GeAs}_{3} \mathrm{Se}_{5}^{-}$clusters. Conditions: negative reflectron ion mode; laser energy $110-140$ a.u; range $450-720 \mathrm{~m} / \mathrm{z}$, relative intensity normalized to $55 \mathrm{mV}$. 


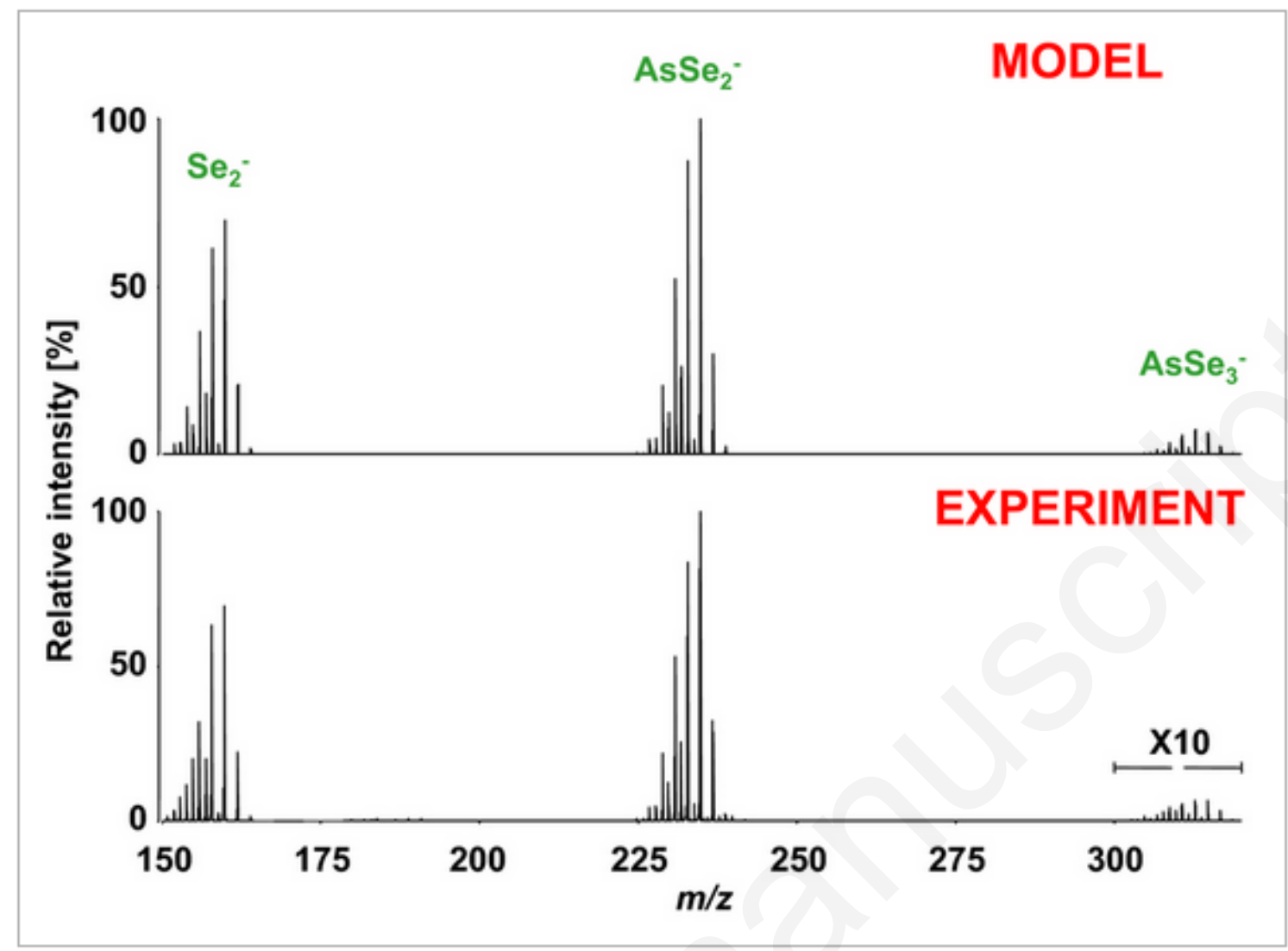

Fig. 3. Selected part of the mass spectrum concerning bulk $\mathrm{Ge}_{10} \mathrm{As}_{30} \mathrm{Se}_{60}$ powdered sample showing the formation of $\mathrm{Se}_{2}{ }^{-}$ion and $\mathrm{AsSe}_{c}{ }^{-}(c=2-3)$ clusters in comparison with theoretical mass spectra. $\mathrm{AsSe}_{3}{ }^{-}$was magnified 10 times. Conditions: negative reflectron ion mode; laser energy 120 a.u; range $150-320 \mathrm{~m} / \mathrm{z}$. 


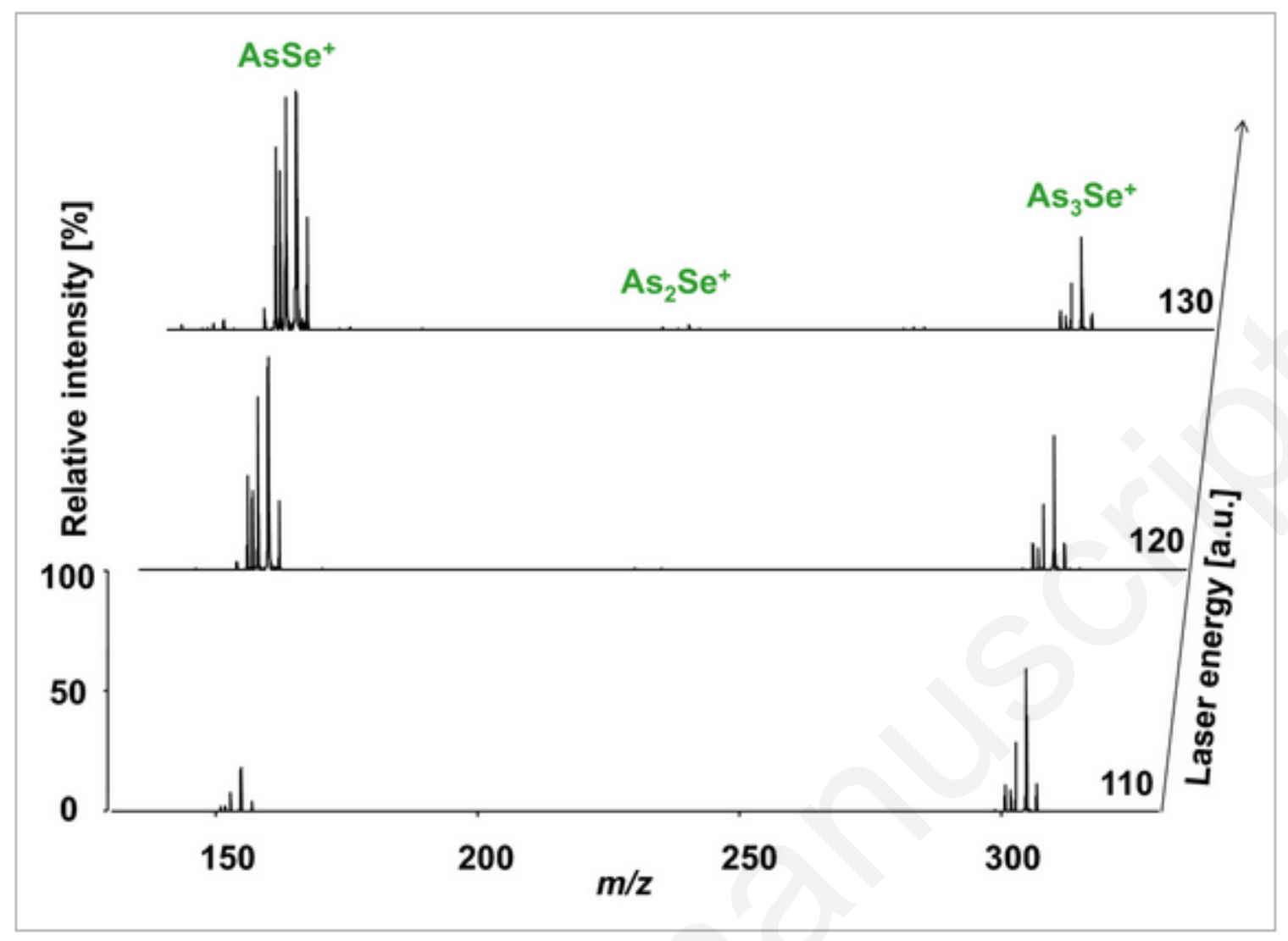

Fig. 4. The effect of laser energy on the LDI TOF mass spectra of the $\mathrm{Ge}_{20} \mathrm{As}_{20} \mathrm{Se}_{60}$ thin film showing the formation of $\mathrm{As}_{b} \mathrm{Se}^{+}(b=1-3)$ clusters. Conditions: positive reflectron ion mode; laser energy 110-130 a.u; range 130-330 m/z, relative intensity normalized to $4995 \mathrm{mV}$. 


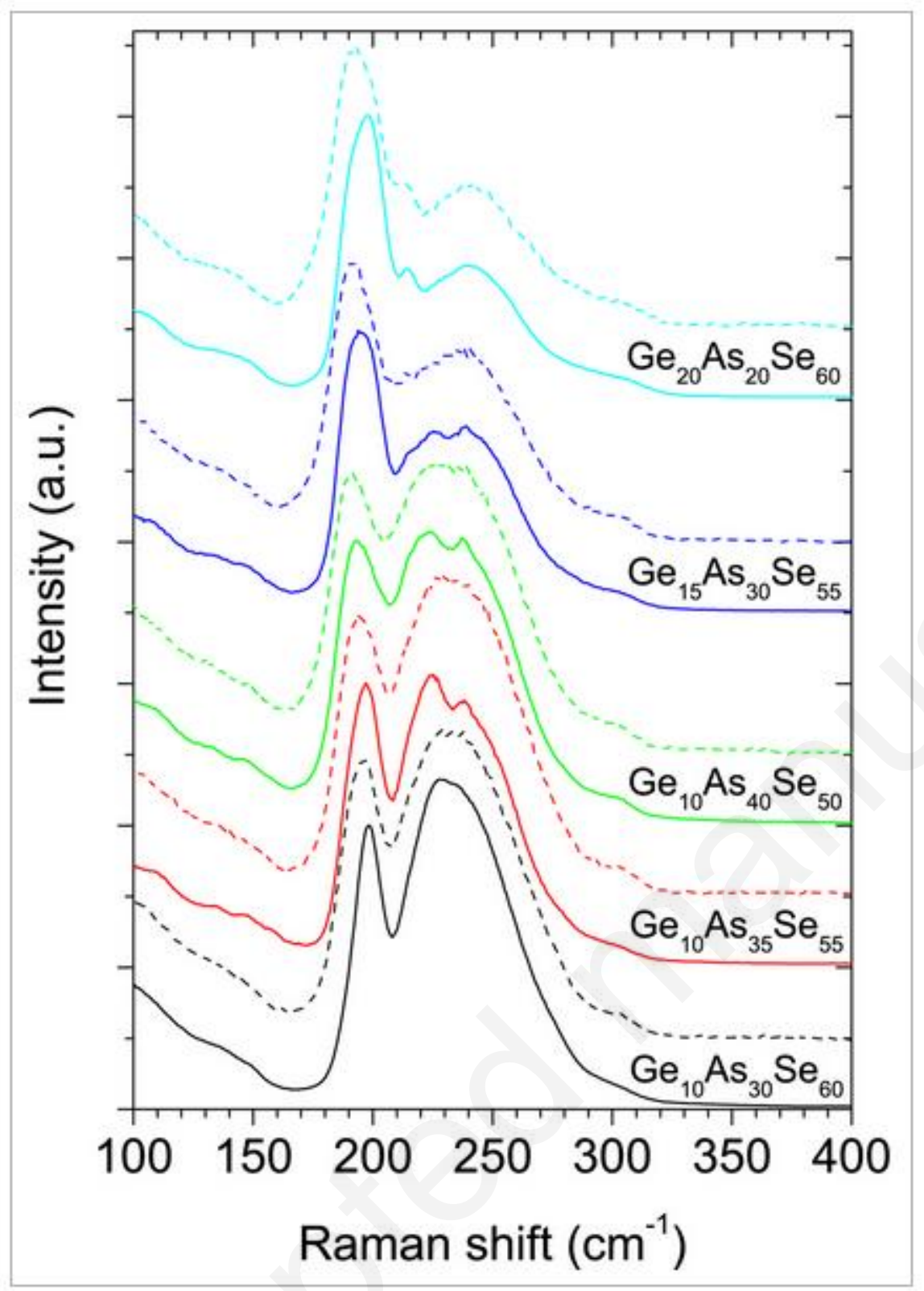

Fig. 5. Raman scattering spectra of Ge-As-Se bulk glasses (full curves) and corresponding thin films prepared by pulsed laser deposition (dashed curves). 


\section{Tables}

Table I. Summary of positively or negatively charged species identified in mass spectra of Ge-As-Se bulk glasses and PLD thin films.*

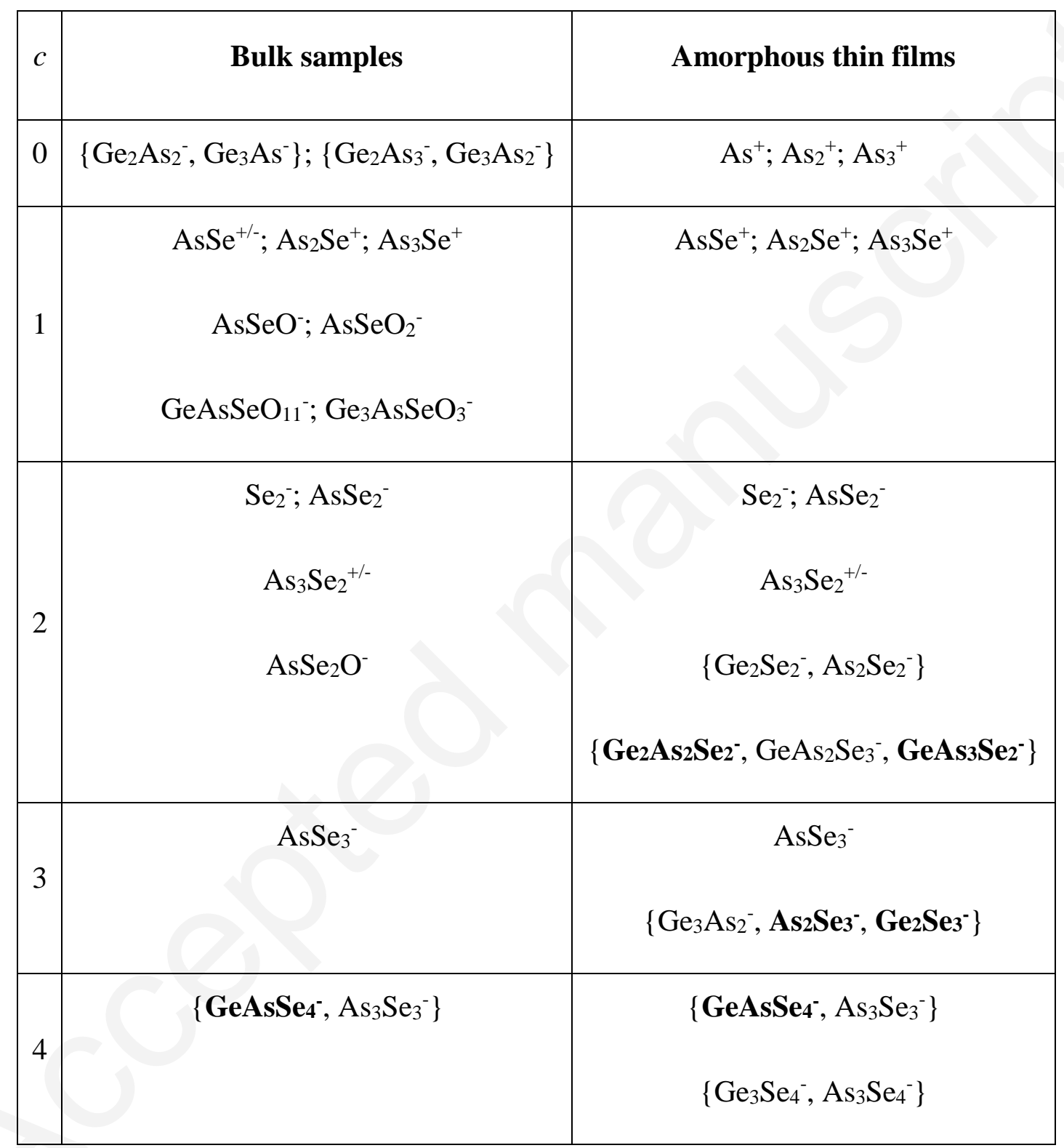

${ }^{*}$ For clarity, $\mathrm{Ge}_{a} \mathrm{As}_{b} \mathrm{Se}_{c}$ formula convention is used for identification of individual species; $c$ stands for the number of selenium atoms in the clusters. Note that overlapping clusters (isobars) are given inside the \{\} brackets; in case of overlap of clusters with different $c$, cluster(s) related to proper $c$ are in boldface. 


\begin{tabular}{|c|c|l|}
\hline 5 & $\mathrm{GeAsSe}_{5}{ }^{-} ; \mathrm{Ge}_{2} \mathrm{AsSe}_{5}{ }^{-}$ & \\
\hline 6 & $\mathrm{Ge}_{3} \mathrm{AsSe}_{5}^{-} ; \mathrm{Ge}_{4} \mathrm{AsSe}_{5}^{-}$ & \\
\hline 7 & $\left\{\mathbf{G e}_{2} \mathrm{AsSe}^{-}, \mathrm{GeAs}_{3} \mathrm{Se}_{5}^{-}, \mathrm{As}_{5} \mathrm{Se}_{4}^{-}\right\}$ & \\
\hline $\left.\mathbf{G e}_{2} \mathrm{AsSe}_{7}{ }^{-}, \mathrm{GeAs}_{3} \mathrm{Se}_{6}{ }^{-}, \mathrm{As}_{5} \mathrm{Se}_{5}^{-}\right\}$ & \\
\hline
\end{tabular}

